\title{
1 Towards the efficient recycling of alloying elements from End of Life Vehicle steel scrap
}

$8 \quad{ }^{\mathrm{a}}$ Graduate School of Environmental Studies, Tohoku University, Miyagi 980-8579,

9 Japan. fy11041@mail.kankyo.tohoku.ac.jp, +81-22-795-7305

10

12 hajime.ono@yale.edu; +1-203-214-9305

13 (Present address)

14

15

16

17

18

24 Corresponding author:

25 Hajime Ohno

26

27

28

${ }^{\mathrm{b}}$ Graduate School of Engineering, Tohoku University, Miyagi 980-8579, Japan. matsubae@m.tohoku.ac.jp, t-nagasaka@m.tohoku.ac.jp,_81-22-795-7304

${ }^{\mathrm{c}}$ Center for Material Cycles and Waste Management, National Institute for Environmental Studies, Ibaraki 305-8506, Japan. nakajima.kenichi@nies.go.jp,+81-29-854-2744

${ }^{\mathrm{d}}$ Faculty of Political Science and Economics, Waseda University, Tokyo 169-8050, Japan.ykondo@waseda.jp, nakashin@waseda.jp.

Center for Industrial Ecology, School of Forestry and Environmental Studies, Yale University, 195 Prospect Street, New Haven, Connecticut 06511, United States.

hajime.ono@yale.edu, +1-203-214-9305 
Abstract

There has been a sharp increase in the production of automobiles over the past decade. In 2010, one billion automobiles were in circulation worldwide. The automobile industry is one of the largest metals consumers and plays an important role in their sustainable use. Steel materials, including alloy

34 steels that contain alloying elements (AEs) such as manganese, chromium, nickel, and molybdenum, are

35 the main component of automobiles. The recycling of end-of-life vehicles (ELVs) significantly affects the

36 cycling of iron, steel, and AEs. Currently, ELV recycling is performed using the electric arc furnace

37 (EAF). In this method, losses of AEs are likely to occur because their presence is rarely considered. This

38 study evaluated the environmental and economic benefits of alternative ELV recycling schemes, which

39 allow more efficient utilization of AEs found in ELV-derived steel scrap (ELV-dSS). The AE contents in

40 ELV-dSS (as car-parts) were estimated by means of a waste input-output material flow analysis (WIO-

41 MFA) model extended for the detailed analysis of automobile composition. Using Japanese data, it was

42 found that sorting ELV-dSS by parts can result in a significant recovery of AEs; more specifically, a 10-

43 fold saving in AEs was achieved by sorting exhaust parts. The recoverable mass of AEs from sorted ELV-

44 dSS was found to correspond to $8.2 \%$ of the annual consumption of AEs in Japan, as virgin resources in

45 EAF steelmaking. ELV-dSS sorting was found to be significantly effective in the conservation of AE 46 resources.

48 Keywords: End-of-life vehicle; alloying element; scrap steel; metals recycling; electric arc furnace; waste 49 input-output material flow analysis 


\section{Introduction}

The proficient management of resources is indispensable for realizing a sustainable society. Metals are considered as essential resource in the modern society, and their efficient use is a key for sustainable development (Gaustad et al., 2011; Graedel et al., 2012; Reck and Graedel, 2012). Reck and Graedel (2012) noted that the recycling of metals from end-of- life (EoL) products has become more complicated and challenging due to the complex structure and composition of contemporary functional products. Metals are typically used in combination and/or alloyed with other products. Unintentional alloying and dissipation may occur as a result of the thermodynamic properties of metals in recycling (Nakamura et al., 2011; Ohno et al., 2014). Efficient recovery of metals from EoL products requires careful deliberation of the recycling methods (Reck and Graedel, 2012).

The automobile industry is one of the largest metal consumers (Nakajima et al., 2013; Nakamura et al., 2011; Ohno et al., 2014). The production of automobiles has been increasing with global population growth. The International Organization of Motor Vehicle Manufactures (OICA) estimated that by 2010,

64 (OICA), 2012). Thus, the automobile industry plays a vital role in the sustainable use of metals. The main 65 component of automobiles is steel materials; therefore, the recycling of end-of-life vehicles (ELVs) could 66 significantly affect the cycling of iron and steel.

There have been many studies regarding the material flow analysis (MFA) of iron and steel (Daigo

68 et al., 2007; Michaelis and Jackson, 2000; Mueller et al., 2006; Pauliuk et al., 2012; Wang et al., 2007).

69 The studies have mainly been concerned with the quantity-based flow and cycling of iron and steel, highlighting the importance of steel recycling in terms of the depletion of high-grade iron ore and $\mathrm{CO}_{2}$ emission reductions. On the other hand, some recent studies have correctly identified the need for quality

72 assurances, in order to guarantee sustainable material cycles for iron and steel (Hatayama et al., 2014;

73 Nakajima et al., 2013; Nakamura et al., 2011; Nakamura et al., 2012; Pauliuk et al., 2012; Reck et al., 74 2010). 
Owing to the complex usage of metals in automobiles, several problems have been identified in the recycling process of ELV-derived steel scrap (ELV-dSS). The most typical problem is the mixing, and contamination, of other metal materials into ELV-dSS. In the current basic ELV treatments, the nonreusable parts (e.g. air-conditioner coolants and airbags), copper contaminated sources (e.g. wire harnesses), and the reusable components (e.g. the engine) are removed, while the rest of the parts are shredded together to reduce the volume of scrap (Ohno et al., 2014). After shredding, non-ferrous metals are magnetically separated from ferrous metals; the magnetic ferrous materials are collected as carbon steel and recycled as an iron source for electric arc furnace (EAF) steelmaking. Copper removal is an important step in the ELV treatment as it is one of the most concerned contaminants in the recycling of steel: Copper has adverse effects on the workability of steel materials and has an accumulative tendency as the cyclic use of steel depending on thermodynamic distribution during steel recycling (Daigo et al., 2005; Hatayama et al., 2014; Houpert et al., 1997; Nakamura et al., 2011). If ELV-dSS contains a known concentration of copper, it must be diluted to below regulatory limits by adding pure iron during the EAF steel recycling process (Hatayama et al., 2014; Nakamura et al., 2012). Contamination in steel may also be caused by alloying elements (AEs), such as chromium (Oda et al., 2009), which are added to enhance certain properties of steel materials. These AE-enriched steel materials are known as alloy steels, and the various available types are consumed in large quantities by the automobile industry (Nakajima et al., 2013). Although AEs are intentionally added to produce alloy steels, they are a source of contamination in the recycling process. They are often considered unwanted constituents (International Organization for Standardization (ISO), 1987). Furthermore, some AEs tend to oxidize into steelmaking slag, depending on their thermodynamic distribution (Nakamura et al., 2011). In these cases, AEs are dissipated, representing the loss of an otherwise potentially valuable resource (Nakamura et al., 2012).

Alloy steel materials are often present in large quantities in automobiles. For example, high-tensile steels are used in the vehicle frame and stainless steels are used as exhaust parts. AEs are likely to be lost during current ELV recycling, which involves shredding and mixing car-parts of varying composition (Ohno et al., 2014). A solution proposed for this problem is the design of recycling-oriented automobiles, 
101

102

103

104

105

which incorporate the metal combinations that cause less contamination during recycling into their design, in accordance with the thermodynamic distribution tendencies of the metals (Castro et al., 2004; Froelich et al., 2007; Millet et al., 2012). However, this solution does not take into account scrap from conventional vehicles, for which materials cannot be easily recycled separately. Therefore, an appropriate treatment process for efficient ELV-dSS recycling must be developed (Ohno et al., 2014).

Nakamura et al. (2012) estimated that significant reductions in $\mathrm{CO}_{2}$ emissions could be achieved by preventing copper contamination in ELV-dSS and reducing the need for the dilution of copper by the addition of pure iron. Current recycling methods of ELV-dSS operate under strict precautions for the prevention of copper contamination. ELV-dSS with low concentrations of copper has been recycled as an iron source in the EAF steelmaking process (Matsubae et al., 2014a). On the other hand, little, if any, attention has been paid to AE concentrations in current ELV-dSS treatments (Ohno et al., 2014). Recent studies have highlighted the importance of developing an efficient recycling system that prevents the loss of indispensable AEs (Nakajima et al., 2013; Nuss et al., 2014; Ohno et al., 2014). Given the difficulties of removing AEs from the steel matrix under present technological and economic conditions, this study aimed to propose a process of disassembling and collecting parts with similar compositions to minimize losses of AEs, and then evaluate the efficiency of the proposed sorting approach.

This study consists of two parts: first, the AE contents in automobiles and ELV-dSS are estimated by extending the waste input-output material flow analysis model (WIO-MFA model); second, the efficiency of ELV-dSS sorting is evaluated. The WIO-MFA model is a useful top-down approach for estimating nationally averaged material composition of various products (Nakamura and Nakajima, 2005; Nakamura et al., 2007). Japanese data were selected due to the availability of high-resolution input-output (IO) data in terms of metals, while the model itself is applicable to any economy. However, even for Japanese IO data, the resolution is not high enough to allow the material composition estimation of individual automobile parts and components (Nakajima et al., 2013; Ohno et al., 2014). To cope with this problem, substantial disaggregation and rearrangement of automobile related sectors was conducted for the Japanese IO data. This resulted in the highest-resolution IO-based estimates ever available for AE 
127 contents of automobile parts and components. Development of this information base enables us to

128 evaluate the AE saving potential and benefits of sorting ELV-dSS.

129

1302 Method and Data

\section{$131 \quad 2.1$ WIO-MFA}

WIO-MFA enables the estimation of the flow of individual materials associated with the flow of commodities by assessing the material composition of commodities based on IO analysis. Using the IO

134 table adjusted for MFA, the material composition matrix $C_{M P}$ can be calculated using Equation (1).

$$
C_{M P}=\tilde{A}_{M P}\left(I-\tilde{A}_{P P}\right)^{-1}
$$

135 Here, $(i, j)$ element of $\tilde{A}_{M P}$ and $\tilde{A}_{P P}$ represent the coefficient of input $i$ to produce one unit of output $j$

136 accounting for yield losses during production processes, $\tilde{A}_{M P}$ denotes the input of materials $(M)$ for the

137 production of products $(P)$, and $\tilde{A}_{P P}$ represents the input of intermediate products $(P)$ for product 138 production $(P)$.

139 The $(i, j)$ element of the matrix $C_{M P}$ represent the volume of material $i$ that comprises one unit of

140 product $j$. Thus, the column sum of this matrix gives the mass of one unit of output when $\tilde{A}_{M P}$ is

141 measured in mass. When the unit of a product is expressed physically, as one ton for instance, the column

142 sum of the corresponding composition matrix is also one ton. When the product is expressed in monetary

143 form, as one-million Japanese yen, the column sum of the corresponding composition matrix represents

144 the mass per one-million Japanese yen. For further details on the methodology, see Nakamura et al.

145 (2007). 
In previous studies, a high-resolution WIO-MFA table for the simultaneous flow analysis of steel AEs was developed based on the Japanese IO table for 2000 and 2005 (Nakajima et al., 2013; Ohno et al., 2014). These models and data were extended to automobile-related sectors in the present study.

\subsection{Disaggregation of the automobile industry into component sectors}

Aggregated sectors in the IO table occasionally lead to unclear results. Since the car-parts sector is highly aggregated in the IO table for Japan (Ministry of Industrial Affairs and Communications (Japan), 2009), despite the extensive variety of parts, the different origins of the materials in each automobile part cannot be distinguished by the WIO-MFA. Thus, disaggregation of the car-parts sector in the IO table is necessary for a detailed analysis of the material composition and origins of materials in automobiles.

In the IO table for Japan, five sectors are directly related to the automobile industry. The passenger cars, trucks, buses, and other vehicle sectors are the final production divisions for automobiles given in

158 the IO table. The intermediate sectors (motor vehicle body, engine, and car-parts) are designated as inputs 159 to the final production sectors. The car-parts sector is disaggregated into ten categories: suspension, shaft, 160 steering, electrical equipment, interior, transmission, brakes, exhaust, and body parts including others. 161 Certain practices, such as direct inputs of steel materials to the passenger car sector, complicate the determination of the usage of steel materials. The flow of steel materials involving several routes was consolidated by imposing mass balance across all automobile-related sectors. The WIO-MFA table developed in previous studies includes information on the total input of steel materials into the automobile industry (Nakajima et al., 2013; Ohno et al., 2014). By fixing the mass balance of steel material inputs, the uses of steel materials in the production of each component were allocated based on car-part composition data (Japan Environmental Sanitation Center, 2009; Tasaki et al., 2004) and the steel and metal material usage in each part (Special Steel Association of JAPAN, 2002). The detailed procedure of data assembly is included in the appendix. Owing to the lack of detailed information 
170 regarding the inputs of non-metals, energy, and services to produce each part, these inputs were assigned

171 according to the quantity of each part produced (Japan Auto Parts Industries Association, 2007). Although

172 the use of national IO data results in the WIO-MFA model providing the national average composition of

173 products, published practical sampling data for several types of automobiles were utilized for sector

174 disaggregation. Although the use of data from different sources may introduce further uncertainty into the

175 analysis results, it would serve as a useful benchmark for AE content in car-parts given the paucity of

176 published information on this subject.

\section{Results and Discussion}

\subsection{Testing and statistical analysis}

The results generated by the proposed model are compared with actual production statistics. The

181 WIO-MFA findings for the passenger car sector estimated that the total mass of passenger cars was 770

182 kg per one million yen. The mass of each class of engine displacement (under 660 cc, between 660 and

$1832,000 \mathrm{cc}$, and over 2,000 cc) was calculated as 639, 943, and 1,716 kg by multiplying the respective unit

184 prices, according to the actual production results indicated in Table 1 . The masses of the tires, window

185 glass, and natural fibers were not included in the results, as only metals and plastics were selected as

186 target materials in the WIO-MFA. Further information regarding the definition of the sectors was reported

187 in our previous study (Ohno et al., 2014).

188 Table 1: Production volumes, value, and unit price of passenger cars in Japan in 2005, subdivided by 189 engine capacity (Ministry of Industrial Affairs and Communications (Japan), 2009).

\begin{tabular}{ccccc}
\hline Engine displacement & $<660 \mathrm{cc}$ & $660-2,000 \mathrm{cc}$ & $>2,000 \mathrm{cc}$ & Total \\
\hline Production (units) & $1,408,753$ & $3,411,609$ & $4,196,373$ & $9,016,735$ \\
Value (million yen) & $1,169,871$ & $4,178,641$ & $9,352,545$ & $14,701,057$ \\
Unit price & 0.830 & 1.225 & 2.229 & 1.630 \\
\hline
\end{tabular}


(million yen/unit)

190

Compared with sales results from 2005 in Japan, the calculated results for the total mass of

192 passenger cars are in agreement with the real products (Fig. 1). Although the model years of the three

193 samples (indicated by rhombic symbols) differ from those of the analyzed results, they showed similar

194 trends in the WIO-MFA results of each engine displacement.

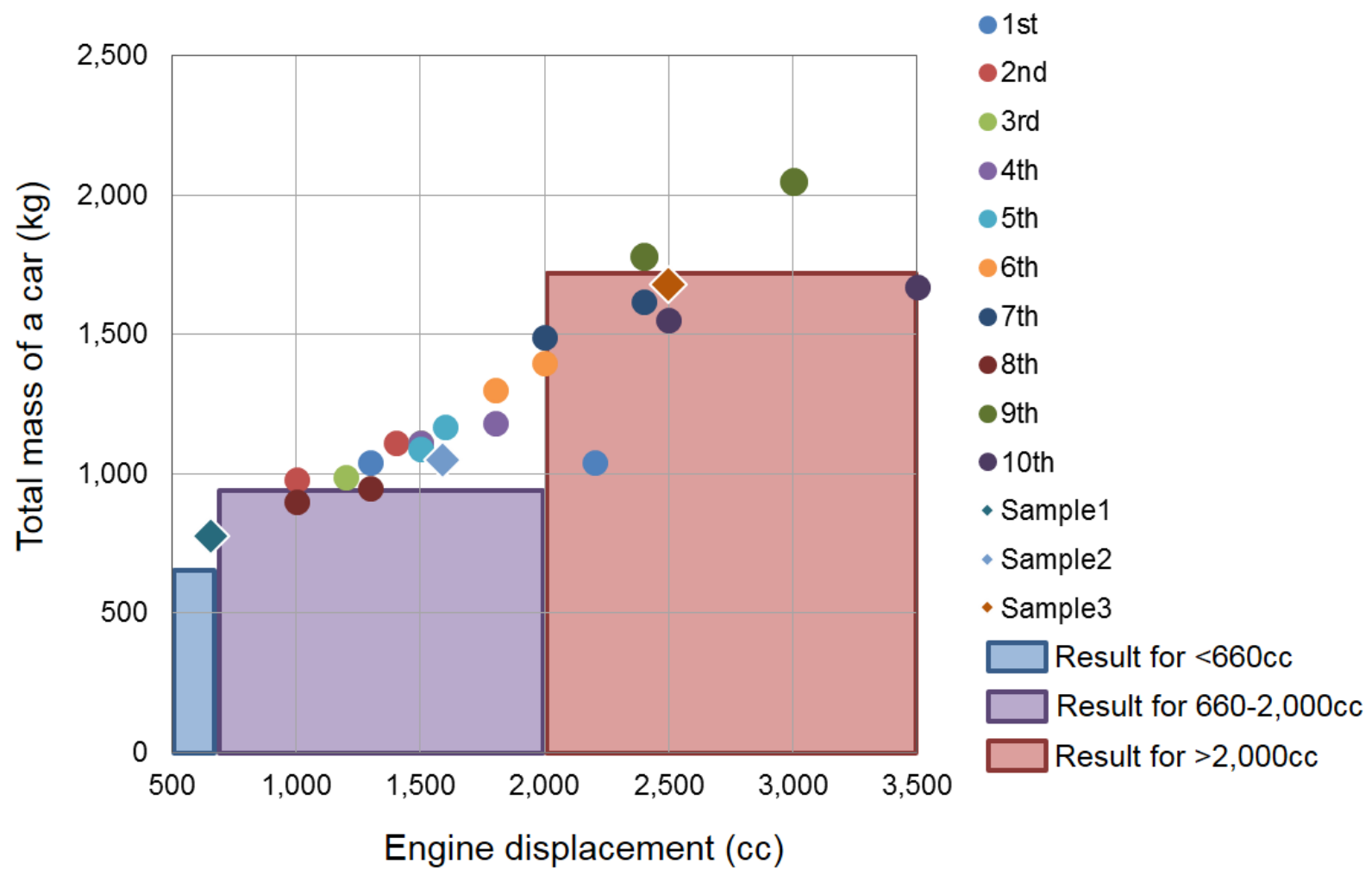

Figure 1: Relationship of total mass of a car and engine displacement for the top 10 cars sold (Japan Automobile Dealers Association, 2005) and the correlation with the results of the waste input-output material flow analysis. The same color marks describe the max and minimum engine displacement and mass for the different grades of the same type of a car. Samples 1 to 3, represent the practical sampling 
results for a light passenger car produced in 1996 (Matsubae et al., 2014a), a middle class passenger car in 1993 (Ministry of Environment (Japan), 2012), and a high class car in 2002 (Japan Environmental Sanitation Center, 2009), respectively.

196

The results of comparing car-part compositions in the three samples show good overall correlation

198 (Fig. 2). However, as the composition of the parts represents the average of all classes of passenger cars, 199 it does not reflect the detailed differences among the classes. For instance, high-class cars with larger

200 engine displacement (Fig. 2, sample 3) tend to use more aluminum parts (Ducker Worldwide, 2012;

201 European Aluminium Association, 2008). Additionally, the classifications of car-parts differ by

202 publication. These disagreements, caused by averaging and inconsistent classification, should be

203 considered a limitation of the analysis. In this study, to simulate averaged ELV-dSS composition, the

204 estimated car weight of middle class passenger cars (660-2,000 cc, $943 \mathrm{~kg})$, which have the highest sales

205 in Japan (Japan Automobile Dealers Association, 2005), is used as the reference sample for car

206 composition.

207 


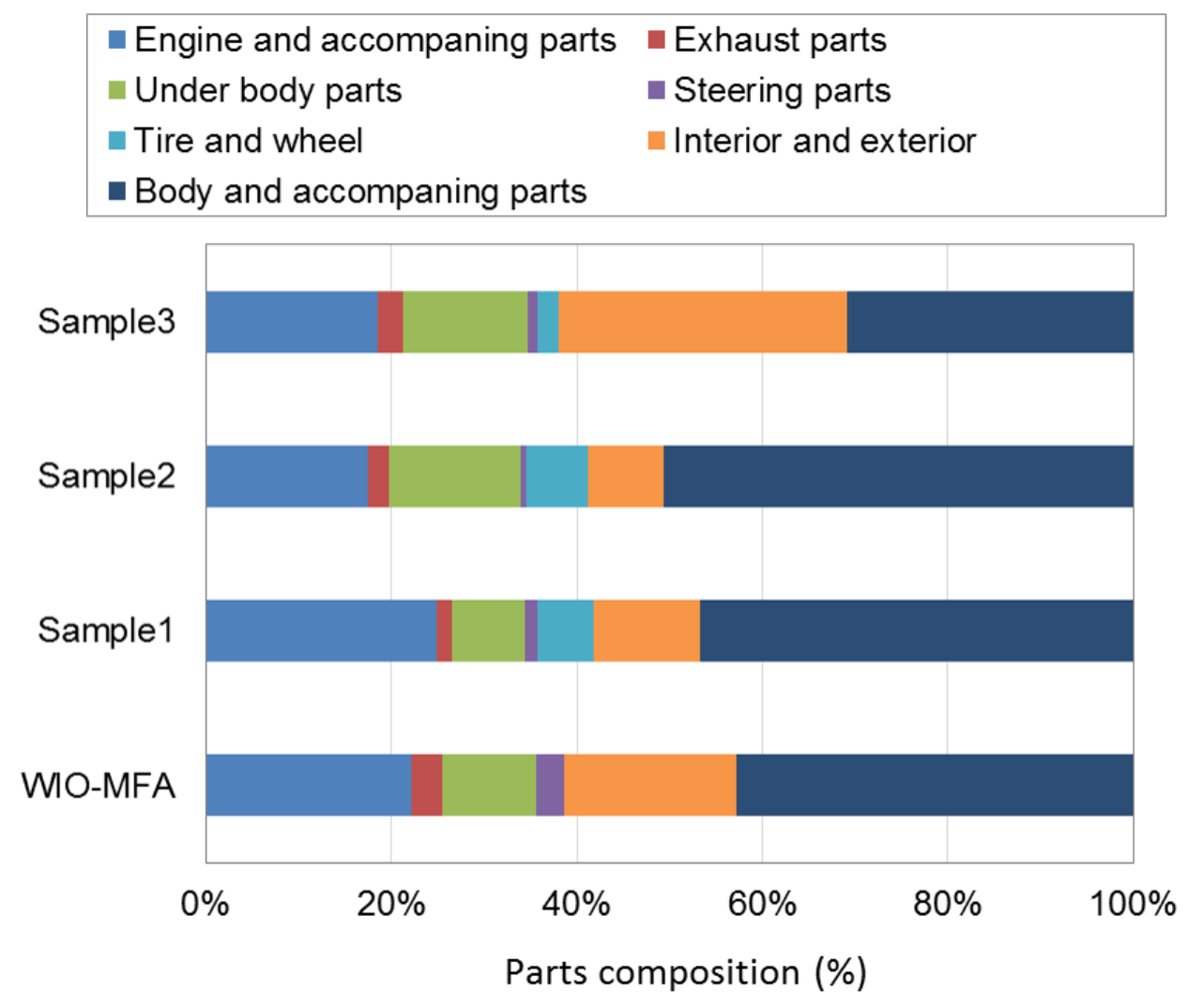

Figure 2: Car-part composition percentages in passenger cars for three samples and estimated results.

Waste input-output material flow analysis (WIO-MFA).

\subsection{AE compositions in different parts of ELV scrap}

Figure 3 illustrates the car-part compositions of a middle class passenger car obtained by WIO-MFA.

210 The unit mass of the passenger car was determined as $943 \mathrm{~kg}$, excluding tires and glass. The amounts of

211 manganese, chromium, nickel, and molybdenum in one passenger car are 3.62, 6.35, 1.50, and 0.19 kg,

212 respectively. The exhaust, which accounts for 3.4\% (31.9 kg) of the total mass of a passenger car,

213 contains large amounts of AEs owing to the use of stainless steel. These are 3.00, 0.71, and $0.06 \mathrm{~kg}$ of

214 chromium, nickel, and molybdenum, respectively. 


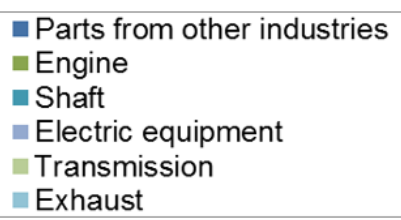

(a)

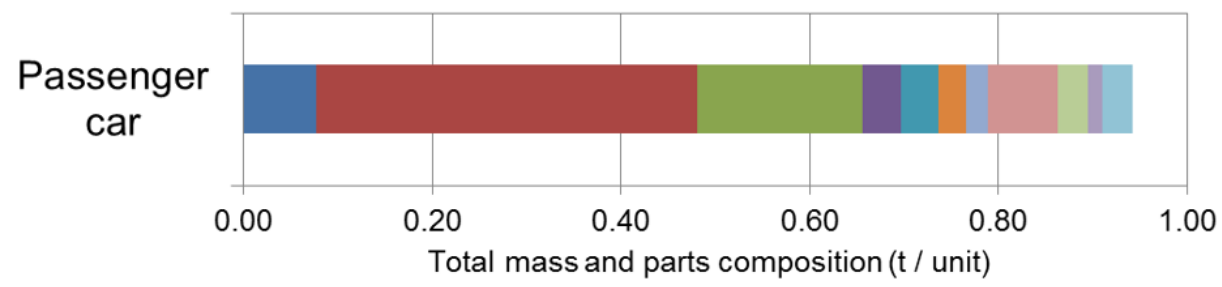

(b)

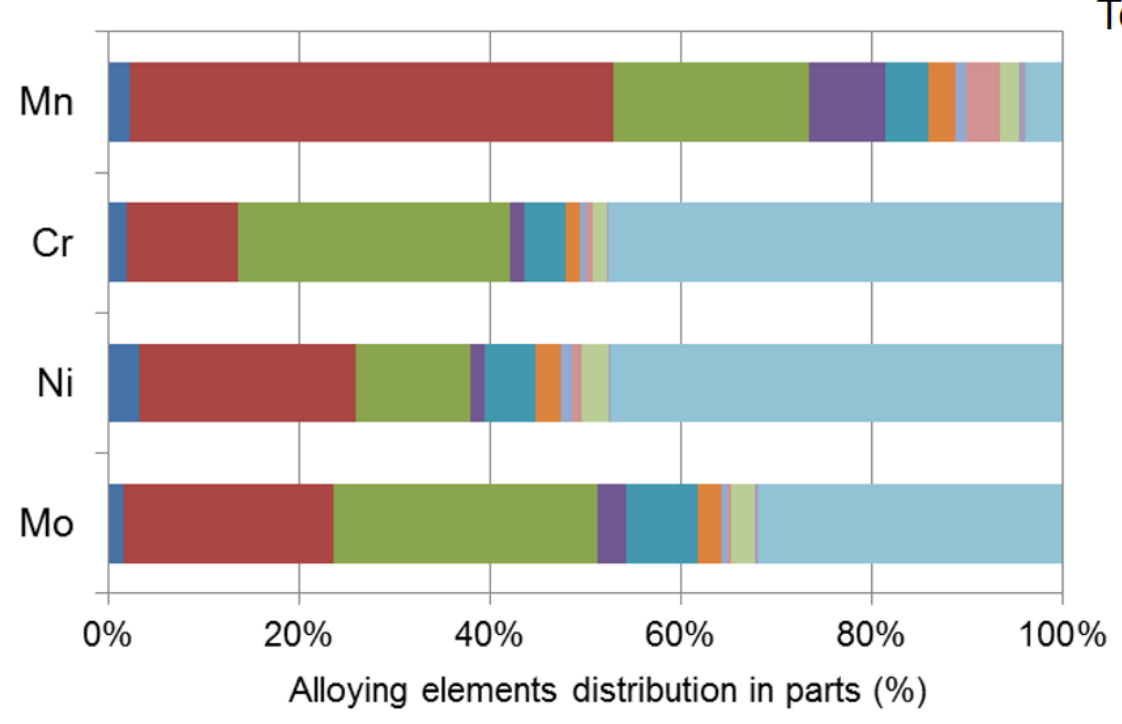

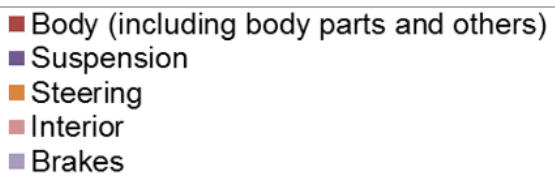

Total contents

\section{$3.6 \mathrm{~kg}$}

$6.4 \mathrm{~kg}$

\section{$1.5 \mathrm{~kg}$}

\section{$0.2 \mathrm{~kg}$}

Figure 3: Car-part composition percentages in a passenger car unit, with the associated concentrations of alloying elements as obtained by waste input-output material flow analysis. (a) details the composition of the parts and components, while (b) gives the percentages of AEs in the corresponding parts. The AEs studied are manganese, chromium, nickel, and molybdenum. The “parts from other industries” category includes all the intermediate products (i.e., those not produced by automobile-related sectors) used in the production of a passenger car. 
The typical ELV treatment in Japan involves the shredding and pressing of the car-parts remaining after the removal of copper and reusable parts such as doors (Ministry of Environment (Japan), 2012;

221 Nakamura et al., 2012; Ohno et al., 2014). Based on the records reported by a Japanese disassembling 222 company (Ministry of Environment (Japan), 2012), it was assumed that the treatment conditions resulted

223 in 100\% of the engine and large copper containing parts (parts from other industries and electric

224 equipment) being removed, and 25\% of the body and interior parts reused and/or recycled. Furthermore, 225 to ship ELV scrap as separated ELV-dSS, it was assumed that treated ELV scrap was shredded separately, 226 part by part, with only steel related metals (iron, AEs, and zinc) remaining for magnetic separation by 227 considering the necessity of volume reduction and removal of non-ferrous and non-metal materials from 228 ELV-dSS. For simplicity, other forms of contamination from sorting errors and/or non-magnetic material 229 were not accounted for, nor were the possible losses during shredding and scrap collection. On the other 230 hand, austenitic (Cr-Ni) stainless steel was included in the analysis. With these assumptions applied to the 231 estimated the passenger car mass (943 kg/unit) and car-part composition, the total mass of the ELV-dSS 232 was estimated as $487 \mathrm{~kg}$, with $2.26 \mathrm{~kg}$ of manganese, $4.18 \mathrm{~kg}$ of chromium, $1.16 \mathrm{~kg}$ of nickel, and $0.12 \mathrm{~kg}$ 233 of molybdenum. The average concentrations of manganese, chromium, nickel, and molybdenum by mass 234 of ELV-dSS were estimated to be $0.46,0.86,0.24$, and $0.02 \%$, respectively. These concentrations of AEs 235 represent the composition of mixed ELV-dSS without sorting. The concentration of AEs differs among 236 car-parts (Fig. 4), indicating that mixing will result in diluting the higher concentrations of some parts 237 with the lower concentrations of other parts. Exhausts are characterized by high concentrations of 238 chromium, nickel, and molybdenum (10.10, 2.37, and $0.20 \%$ respectively), because of the use of stainless 239 steel. The manganese concentration in the suspension (0.72\%) is higher than the average concentration in 240 ELV-dSS. Similarly, parts with lower AE concentrations, such as the body and brakes, are contaminated 241 through mixing with high AE concentration parts. Consequently, the mixing of different parts can cause 242 loss in quality of both AEs and steel (Nakamura et al., 2012). Some AEs (such as manganese and 243 chromium) in mixed ELV-dSS transferred to EAFs oxidize easily and form slag (Nakajima et al., 2011).

244 While other AEs that tend to remain in molten steel (such as nickel and molybdenum) are diluted with 
primary iron to meet quality requirements (Nakamura et al., 2011). Consequently, the recycling of mixed

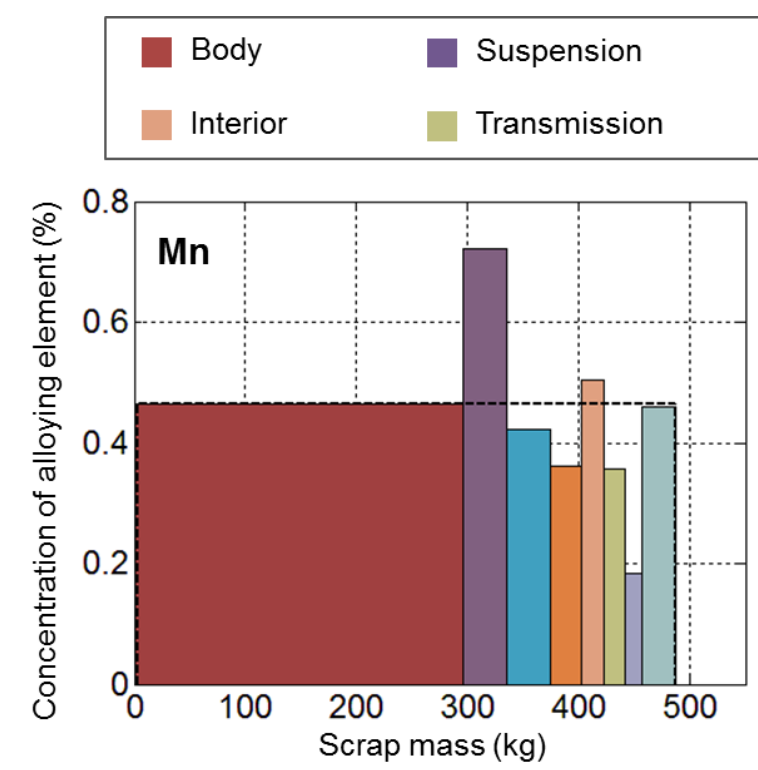

$\begin{array}{lll}\text { Shaft } & \text { Steering } & \\ \text { Brakes } & \text { Exhaust }\end{array}$
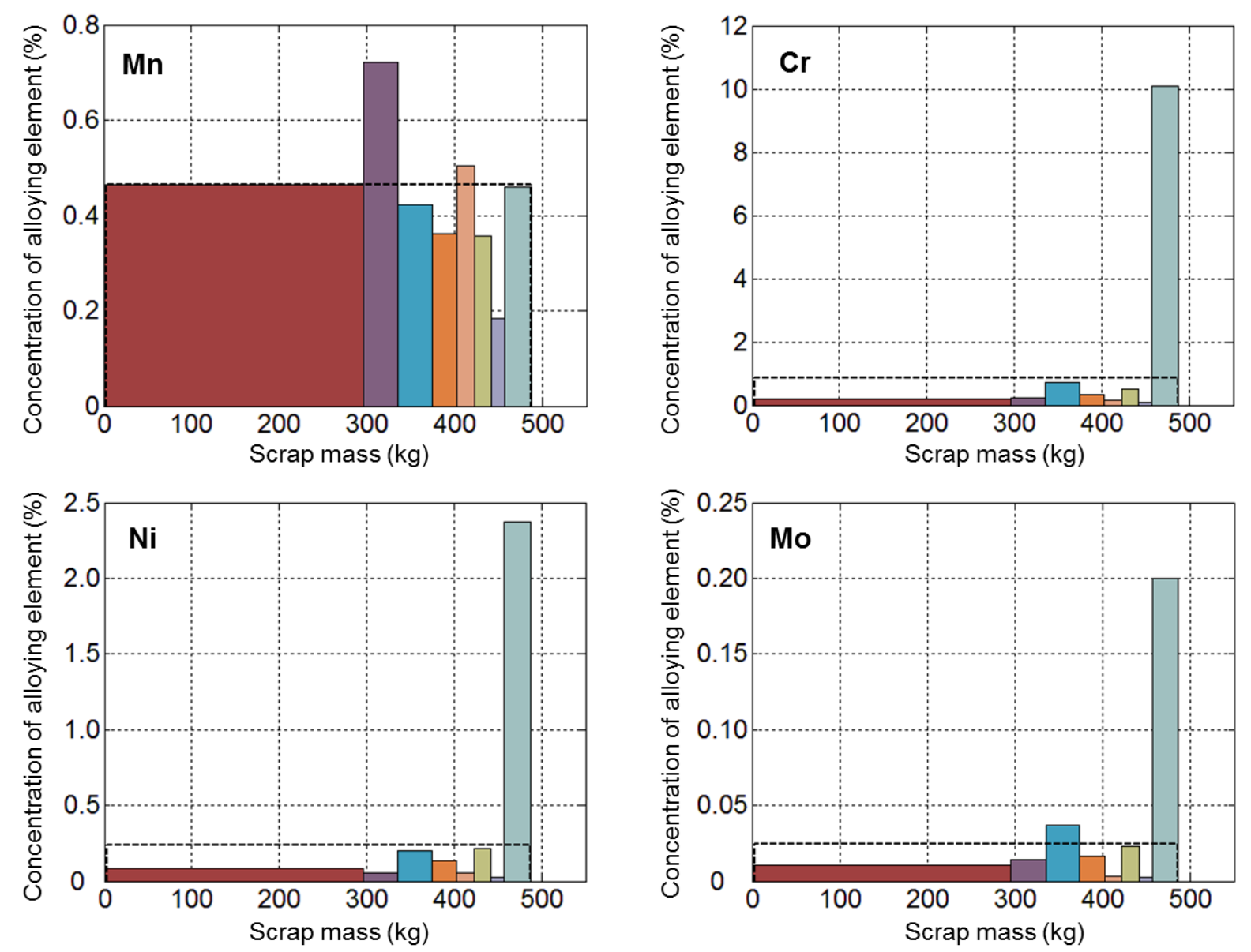

Figure 4: Mass of the treated ELV-derived steel scrap by parts and the concentrations of alloying elements. Y-axes of the graphs have the same units, but the scales are different for each alloying element.

The results suggest that switching from the current practice of mixed treatment to sorting by parts can reduce AE losses. Accordingly, producing secondary steel materials from sorted ELV-dSS with 
251 similar alloy compositions can reduce the consumption of virgin sources of AEs, such as ferroalloys.

252 Applying estimated ELV-dSS composition to the 2005 actual recycled scrap volumes in Japan (2,348 kt),

253 the mass of each scrap part and their accompanying elements can be estimated (Table 2). Adding the mass

254 of removed parts, the total mass of treated ELV was estimated as 4,548 kt. Considering the mass of one

255 unit of automobile in this study (943 kg), the number of discarded ELVs was estimated as 4.8 millions.

256 Since around four to five million units of ELVs are discarded in Japan every year (Tasaki et al., 2004), it

257 can be said that the assumptions for ELV treatment conditions in this study are not far from the reality in

258 terms of mass. The total amount of AEs contained in 2,348 kt of recycled ELV-dSS correspond to 10.5\%

259 of the amount of virgin AEs annually consumed in EAF crude steelmaking (Ministry of Economy, Trade

260 and Industry (Japan)2006). Despite the considerable amount of AEs contained in ELV-dSS, about 93\% of

261 ELV-dSS is currently recycled to carbon steels that require lesser amounts of AEs than alloy steels

262 produced by the EAF steelmaking process (Ohno et al., 2014). Therefore, the present recycling of ELV-

263 dSS is inefficient when it comes to the use of AEs.

264 A caveat to the above result is the disregard of the time lag between the production and the end of

265 lifetime. As Nakamura et al. (2014) stated, the materials contained in products are serially recycled

266 according to the lifetime distribution of products. The results above were obtained by assuming that the

267 composition of all ELV-dSS recycled in 2005 is equal to the composition of cars produced in 2005. This

268 is a strong assumption that disregards any possible changes in material composition, weight, and type of

269 cars over time. Relaxation of this strong assumption would require a dynamic extension of the current

270 framework, including possible changes in car composition over time, which is an important direction for

271 future research.

272 
274 Table 2: Estimated amounts of treated scrap by parts, in 2005, and their composition of alloying elements.

\begin{tabular}{lccccc}
\hline & Scrap mass & \multicolumn{4}{c}{ Alloying elements (t) } \\
\cline { 3 - 6 }$(\mathrm{kt})$ & 1,424 & 6,608 & 2,680 & 1,230 & 149 \\
\hline Body & 194 & 1,403 & 436 & 113 & 27 \\
Suspension & 185 & 779 & 1,324 & 376 & 68 \\
Shaft & 139 & 502 & 470 & 191 & 23 \\
Steering & 93 & 471 & 138 & 54 & 3 \\
Interior & 96 & 342 & 479 & 204 & 22 \\
Transmission & 72 & 132 & 52 & 18 & 2 \\
Brakes & 144 & 662 & 14,562 & 3,415 & 289 \\
Exhaust & 2,348 & 10,898 & 20,141 & 5,600 & 583 \\
\hline ELV-dSS total & 2,200 & 6,892 & 10,608 & 1,660 & 324 \\
\hline Removed & 4,548 & 17,790 & 30,748 & 7,260 & 907 \\
\hline Total & & &
\end{tabular}

275

276

277

278 


\subsection{Scrap sorting to prevent the loss and dilution of AEs}

Prevention of AE dissipation in ELV-dSS recycling calls for appropriate scrap sorting. Here, a

281

282

283

284

285

286

287

288

289

290 simple ELV-dSS sorting scenario is considered, sorting ELV-dSS into three types of scrap, A, B, and C. Suspension parts are sorted into Scrap A to retain their high manganese content. Exhaust parts, which are characterized by the highest concentration of chromium, nickel, and molybdenum, are sorted as Scrap B. The remainder of the parts is considered Scrap C. This simple sorting process was found to be effective in reducing both the dilution of AEs and the contamination of iron (Fig. 5). Figure 5 shows the ratio of AE concentrations contained in each of the three scrap categories to the averages of mixed scrap without sorting, defined as the concentration ratio. It confirms the effects of sorting on concentrating AE (above 1) and purifying iron matrices (less than 1). Sorting Scrap A resulted in about a 1.5-fold concentration of manganese, but no significant purification of iron matrices. The latter can be attributed to the wide range usage of manganese in the steel materials for automobiles. On the other hand, sorting of Scrap B was found to result in significant concentration of 10-fold for chromium, nickel, and molybdenum.

The three scrap categories are defined in a straightforward fashion and can be applied rather easily to the practice of steel making. Scrap A would be suitable for manganese requiring steel, such as spring steel (International Organization for Standardization (ISO), 2004), which is composed of 0.6 to $1.0 \%$ of manganese. Scrap B would be appropriate for austenitic (nickel containing) stainless steel requiring higher concentrations of chromium and nickel. In addition, because some separated parts contain higher concentrations of AEs, Scrap C is less contaminated (Fig. 5). Thus, EAF steelmakers can use Scrap C as a high-grade iron source for various grades of steel production. Although the concentration of manganese is not significantly changed by scrap sorting, manganese contained in scrap can work as both AE and a deoxidizing agent in steelmaking (Nakajima et al., 2008; Nakamura et al., 2011). 

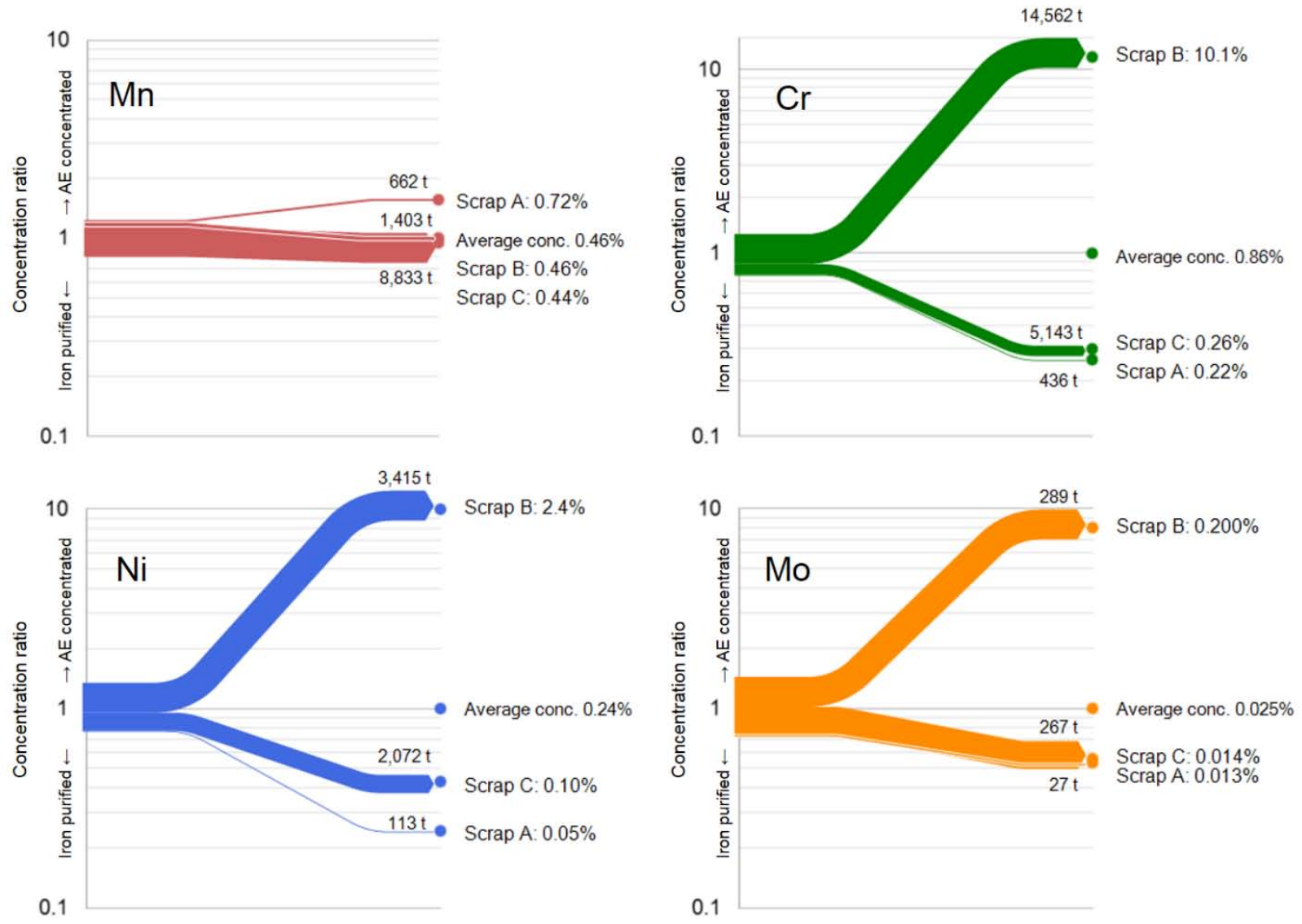

Figure 5: Improvements in alloying elements purities by scrap sorting into three categories (A, B, and C).

Prior to sorting, the percentages of chromium and nickel in ELV-dSS were $0.86 \%$ and $0.24 \%$, respectively. The summed concentration of chromium and nickel cannot exceed $0.35 \%$ for some low-

306 alloyed steel materials (International Organization for Standardization (ISO), 1987). Approximately 5,000

307 kt of other iron sources are required to dilute the chromium and nickel contained in 2,348 kt of mixed ELV-dSS to achieve the target concentration. This means a significant loss of quality for iron (Nakamura et al., 2012). In contrast, the sorted Scrap $C$ would require minimal dilution because the summed 310 concentration of chromium and nickel is $0.36 \%$. The practical recyclability of Scrap C, requiring less 
311 dilution with iron, would be significantly beneficial in terms of the reduction pig iron production and the

312 associated energy requirements and $\mathrm{CO}_{2}$ emissions.

\section{3.4 Virgin resource saving potential and its effect for environment and economy}

314 Table 3 presents the estimated amounts of AEs that can be substituted for virgin resources. Further

315 to the discussion in Section 3.3, the entire manganese content of ELV-dSS was assumed recoverable. For

316 other AEs, only Scrap B mass compositions were considered recoverable.

317 Table 3: Recoverable amounts of AEs from ELV-dSS and equivalent amounts of ferroalloys.

\begin{tabular}{|c|c|c|c|c|c|c|}
\hline Virgin resource saving & & Mn & $\mathrm{Cr}$ & $\mathrm{Ni}$ & Mo & Total \\
\hline Recoverable mass (t) & & 10,898 & 14,562 & 3,415 & 289 & 29,163 \\
\hline Recovery ratio (\%) ${ }^{a}$ & & 100 & 72 & 61 & 50 & 78 \\
\hline \multirow[t]{2}{*}{$\begin{array}{l}\text { Corresponding to annual } \\
\text { consumption in EAF (\%) }\end{array}$} & & 10.0 & 7.6 & 7.7 & 3.5 & 8.2 \\
\hline & Average ${ }^{c}$ & 78 & 57 & 28 & 62 & \\
\hline \multirow[t]{3}{*}{ Contents in ferroalloy (\%) } & Lowest $^{\mathrm{d}}$ & 73 & 55 & 16 & 55 & \\
\hline & Highest $^{\mathrm{d}}$ & 85 & 70 & 28 & 70 & \\
\hline & Average & 13,971 & 25,547 & 12,197 & 466 & 52,181 \\
\hline \multirow[t]{2}{*}{ Ferroalloy equivalent (t) } & Lowest & 14,928 & 26,476 & 21,344 & 525 & 63,274 \\
\hline & Highest & 12,821 & 20,803 & 12,197 & 412 & 46,233 \\
\hline
\end{tabular}

a: Percentage of recovered AE mass / AE contained in ELV-dSS

b: Percentage of recovered AE mass / annual consumption of AE in Japanese EAF in 2005

c: Japan Oil, Gas and Metals National Corporation (JOGMEC), 2007

d: ISO 5446 (1980), ISO 5448 (1981), ISO 6501 (1998), ISO 5452 (1980) 
Figure 6 gives the estimated amounts of greenhouse gas (GHG) emissions and imports of virgin AE

320 resources that result from the proposed sorting procedure. It was estimated that a total of 318 to $609 \mathrm{kt}-$

$321 \mathrm{CO}_{2}$ eq of emissions can be reduced in the production of ferroalloys, which corresponds to $8.6 \%$ to $16.4 \%$

322 reduction in the emission from ferroalloy production in Japan. The total saving for electricity and fuel-

323 derived energy were also evaluated as 212 to 319 GWh and 1,641 to 2,265 GJ, respectively, which

324 correspond to $7.6 \%$ to $11.4 \%$ of electricity and $5.8 \%$ to $8.1 \%$ of fuel-derived energy for ferroalloy

325 production in Japan (Agency for Natural Resource and Energy, 2005). The amount of ferroalloys

326 recovered corresponded to 5.0\% of all imported ferroalloys in 2005 (Ministry of Industrial Affairs and

327 Communications (Japan), 2009), which represents a saving of about 13 billion yen. These results

328 represent the non-negligible contribution of efficient ELV-dSS recycling to both the environment and

329 economy, despite the modest 6.8\% share of ELV-dSS in purchased steel scrap (The Japan Ferrous Raw

330 Materials Association, 2006). 


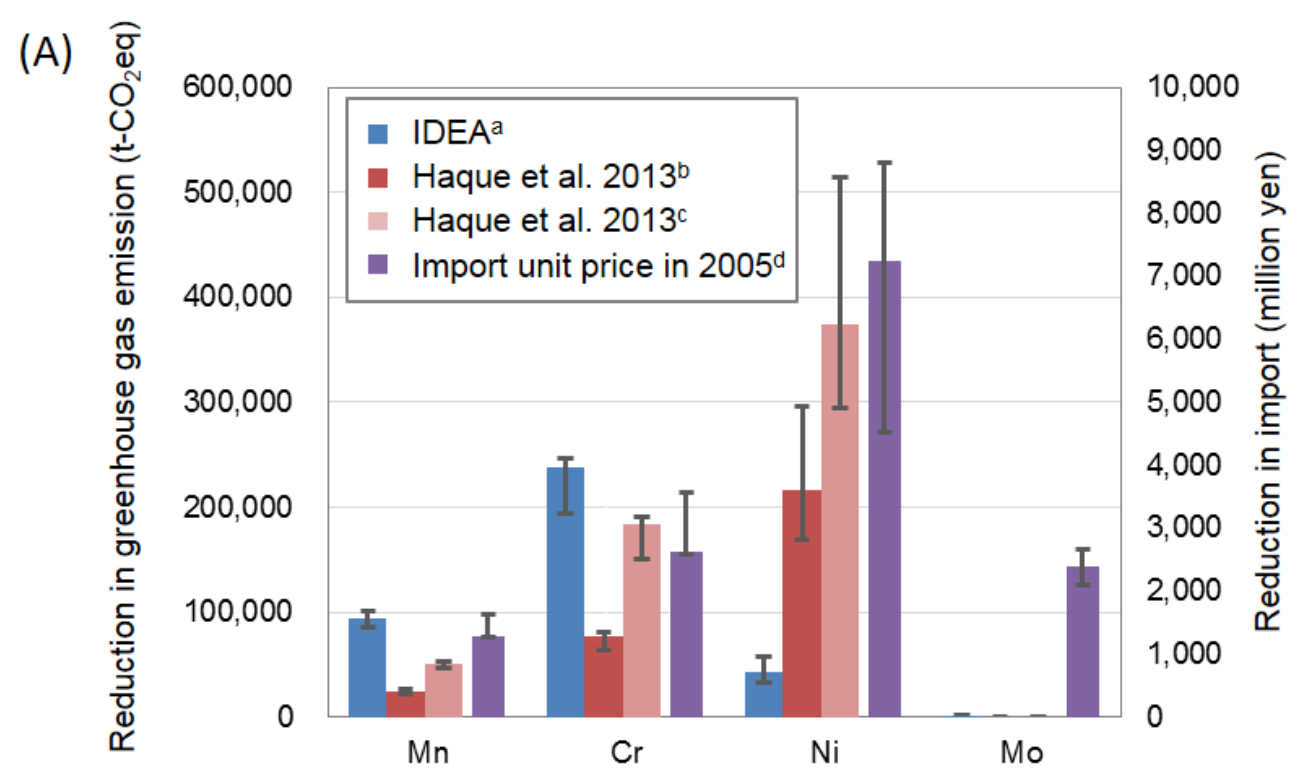

(B)

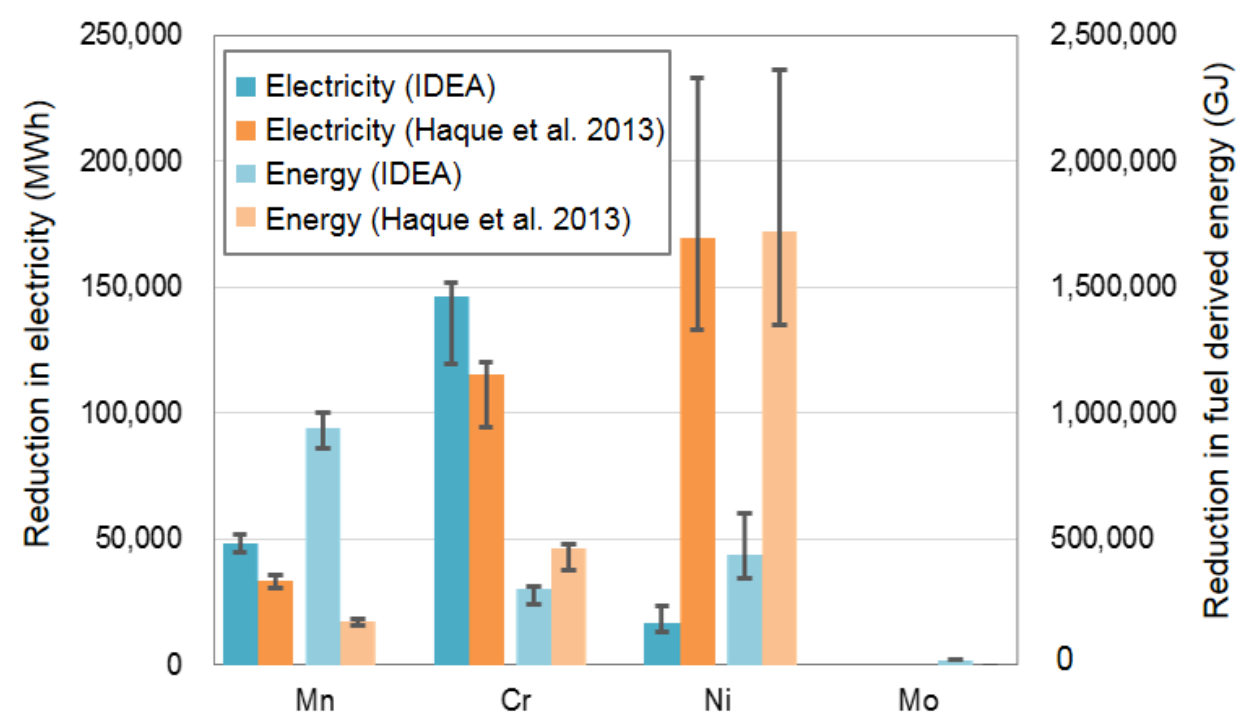

Figure 6: Potential reductions in (A) greenhouse gas emissions, imports, and (B) electricity and fuelderived energy, due to the decrease in the use of virgin resources following appropriate ELV-dSS utilization. Error bars indicate the variability between highest (bottom) and lowest (top) alloying element concentrations in ferroalloys. For molybdenum, data was not available from Haque et al., 2013. a: Inventory Database for Environmental Analysis, Japan; b: Mixed fuel (mainly hydro-power, gas, and coal) electric generation, Tasmania, Australia; c: Australian average (mainly coal and gas fuel) electric generation, Australia; d: Trade Statistics of Japan. 
332

334

335

336

337

338

339

340

341

342

343

344

345

\section{Discussion and conclusion}

This study has shown the considerable potential of ELVs as secondary sources of material. Efficient utilization of ELV-dSS by sorting will play an important role in resource dissipation prevention and conservation. It was found that the introduction of a rather simple sorting scheme for ELV-dSS, containing three parts (suspension parts, exhaust parts, and others), can be beneficial for the environment and the economy. This finding gives an alternative option for ELV recycling that focuses on the use of the AE content, which differs from previous recycling schemes that regard ELV-dSS as an iron source (Matsubae et al., 2011; Simic and Dimitrijevic, 2013). Furthermore, a variety of scrap compositions can be obtained under different ELV treatment scenarios, based on the national average automobile composition. Utilizing the features of the model, a useful comprehensive decision can be made to support policy makers and ELV treatment stakeholders. Considering the average lifetime of automobiles (Hatayama et al., 2010), many automobiles produced in 2005 will not reach EoL and be discarded until several years later. Since the model simulated the scrap composition of automobiles produced in 2005, the results would also be useful for estimating the requirements of ELV recycling in the near future.

Appropriate ELV-dSS utilization, based on sorting, has significant potential for cost savings and virgin material import reduction. This may motivate ELV treatment stakeholders and EAF steelmakers to use appropriately sorted ELV-dSS. However, this form of ELV treatment has rarely been implemented in practice (Froelich et al., 2007; Japan Environmental Sanitation Center, 2009; Matsubae et al., 2014a; Matsubae et al., 2014b).

In our previous study, potential obstacles for the implementation of scrap sorting were identified (Ohno et al., 2014) as gaps in knowledge and the attitude between steel production companies and ELV recyclers, and the absence of affordable efficient sorting technologies. The results of this study can provide some solutions to these issues. For ELV recyclers, sorting the ELV scrap into the three proposed categories would be easy, without the need for detailed information about the material compositions or 
substantial additional investments in the facility. It also enables steelmakers to use ELV-dSS with relative ease, using a basic level of understanding of the standard AE contents in ELV-dSS.

Another obstacle identified in the previous study was the problem of the steel scrap market, which poses a challenge to the implementation of the scrap sorting methodology proposed in this study. In the current market, scrap is classified and traded almost exclusively based on its shape with almost no

361 consideration of the value of its alloy content (European Ferrous Recovery and Recycling Federation,

362 2007; Institute of Scrap Recycling Industries (ISRI), 2013; The Japan Ferrous Raw Materials Association, 363 2008). This situation in the scrap market is likely to discourage ELV recyclers from sorting ELV-dSS on 364 the basis of AE composition (Matsubae et al., 2014b). The amount of AEs present in automobiles is likely 365 to increase with the current trends in the automobile industry (The Japan Iron and Steel Federation, 2013). 366 Coping with this trend of increasing AE content in ELV-dSS, while incorporating sustainable resource 367 use, would call for revisions to scrap grade definition and pricing in the scrap market. Scrap pricing based on AE content would be beneficial to ELV recyclers and encourage them to engage in ELV-dSS sorting. In the present study, the sorting, recycling, and utilization objectives were selected according to the

370 AE concentration of each scrap and steel material in a straightforward manner, without resorting to a 371 systematic optimization algorithm, such as the minimization of virgin-resource use, the environmental 372 impact, and/or cost reduction (Kondo and Nakamura, 2005). AEs differ in terms of resource availability, 373 environmental loads in mining and production, and the value of the resources and materials. The use of 374 different optimization objectives would result in different patterns of optimal sorting. Extending the 375 current model along these lines is an important direction for future research. 
automobiles from the perspective of the material industry), and the Research Institute of Science and Technology for Society of the Japanese Science and Technology Agency.

\section{Appendix. Data preparation for the disaggregation of automobile sectors in the IO table}

In previous studies on the WIO-MFA model, the hot-rolled special steel sector was disaggregated into 19 sector grades (Nakajima et al., 2013; Ohno et al., 2014). Here, “special steel” is defined as the steel added specific properties, including alloy steel. In the previous disaggregation process, the total input amounts of every grade of steel related to automobile sectors were fixed (as shown in the left bars of each sector in Figure A1). There were two problems to be addressed: (1) direct inputs to the final product sectors (passenger car sector, and the bus, truck, and others sector) made the steel material usage unclear; and (2) composition of disaggregated special steel inputs into each sector were the same. In addition to solving these problems, disaggregation of parts sector was carried out in this study.

393 allocated to the parts sectors; the input amounts to the body and engine sectors were unchanged. This 394 means that direct inputs of steel materials to final products were assumed to be indirect inputs to final 395 products in some parts. Through this process, problem (1) was solved and all steel usage in automobiles 396 could be traced. The process for solving problem (2) was operated simultaneously with parts sector 397 disaggregation. Since the body and engine sectors have already been separated, the specific steel usages 398 in these sectors were fixed before the parts sectors. The Special Steel Association of JAPAN (2002) 399 provided relatively detailed information on steel usages and masses in automotive engines. Based on this 400 reference, some grades of special steels such as free-cutting, heat-resistant, and structural steels were 401 fixed as engine inputs. Only high-tensile steel and small amounts of weathering steel were allocated to the 402 body sector, since it does not demand large amounts of special steels. The remainder of the special steels, 
not distributed to the engine and body sectors, were allocated to 10 types of parts based on the reference information (Special Steel Association of JAPAN, 2002).

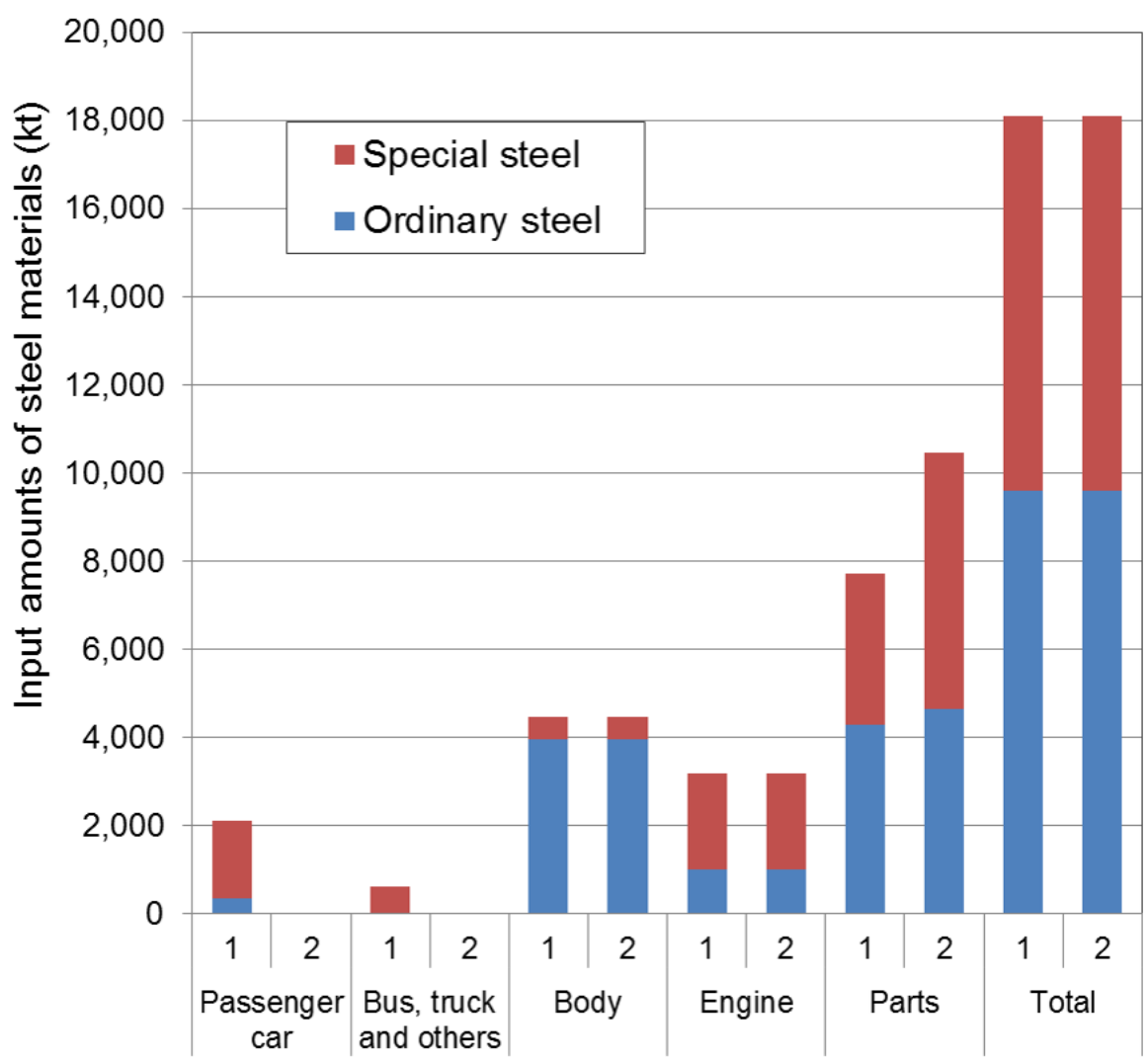

Figure A1: Comparison of steel material inputs for each automobile related sector (1) before and (2) after the disaggregation process.

There was some discrepancy between the total steel demand for parts reported in the reference and

407 the total steel supply reported in the IO table. Since the reference reported the average special steel content in each component of one automobile unit, the steel demand in the parts sectors was estimated by multiplying the number of automobiles produced in 2005 (Table1) and the inverse of the yield ratio of car-parts sector applied in WIO-MFA. The calculated steel demands and the IO based supply were 411 subsequently harmonized by allocating surplus and shortage. More specifically, for structural steels 
412 (carbon and alloy), the surplus was allocated to the "parts for body and others” sector. These data

413 adjustments resulted in some changes in the composition of special steel in each of the components

414 (Figure A2).

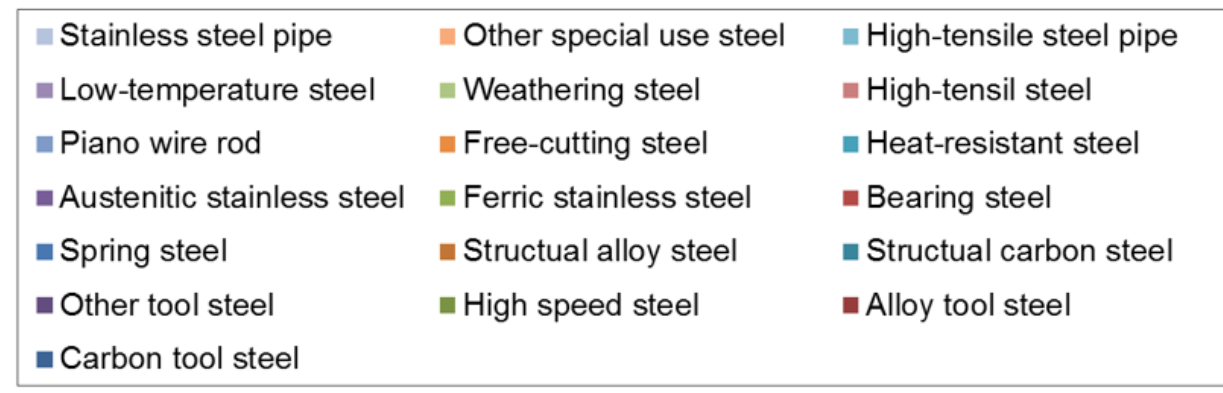

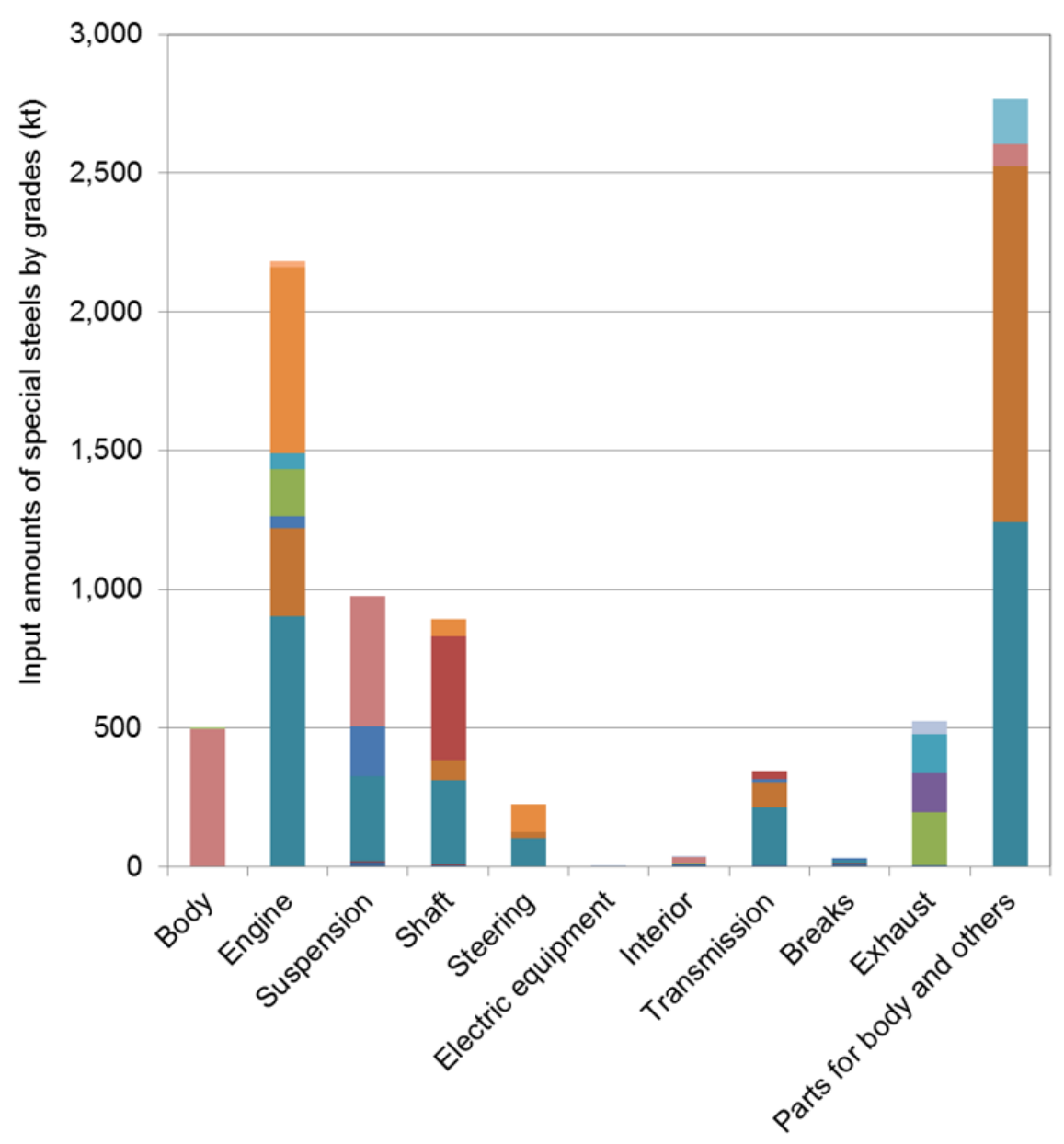

Figure A2: Allocated special steel composition in disaggregated-part sectors 
416 


\section{References}

418 Agency for Natural Resource and Energy. Energy Balance Table.

419 Japan,2005,http://www.enecho.meti.go.jp/statistics/total_energy/results.html\#headline2

420 (accessed January 23, 2015).

421 Castro MBG, Remmerswaal JAM, Reuter MA, Boin UJM. A thermodynamic approach to the

422 compatibility of materials combinations for recycling. Resour Conserv Recy. 2004;43:1-19.

423 Daigo I, Fujimaki D, Matsuno Y, Adachi Y. Development of a dynamic model for assessing environmental impact associated with cyclic use of steel. Tetsu to Hagane. 2005;91:171-8. Daigo I, Igarashi Y, Matsuno Y, Adachi Y. Accounting for steel stock in Japan. Isij Int. 2007;47:1065-9.

Ducker Worldwide. EAA Aluminum Penetration in Cars 2012. 2012.

European Aluminium Association. Alminium in

Cars.2008,http://www.alueurope.eu/pdf/Aluminium_in_cars_Sept2008.pdf (accessed July 29, 2014).

European Ferrous Recovery and Recycling Federation. EU-27 Steel Scrap Specification. Brussels Belgium2007.

Froelich D, Haoues N, Leroy Y, Renard H. Development of a new methodology to integrate ELV treatment limits into requirements for metal automotive part design. Miner Eng. 2007;20:891-901.

Gaustad G, Olivetti E, Kirchain R. Toward Sustainable Material Usage: Evaluating the Importance of Market Motivated Agency in Modeling Material Flows. Environ Sci Technol. 2011;45:4110-7.

Graedel TE, Barr R, Chandler C, Chase T, Choi J, Christoffersen L, et al. Methodology of metal criticality determination. Environ Sci Technol. 2012;46:1063-70. Hatayama H, Daigo I, Matsuno Y, Adachi Y. Outlook of the World Steel Cycle Based on the Stock and Flow Dynamics. Environ Sci Technol. 2010;44:6457-63. Hatayama H, Daigo I, Tahara K. Tracking effective measures for closed-loop recycling of automobile steel in China. Resour Conserv Recy. 2014;87:65-71. Houpert C, Lanteri V, Jolivet JM, Guttmann M, Birat JP, Jallon M, et al. Influence of tramp elements in the production of high quality steels using the scrap electric arc furnace route. Rev Metall-Paris. 1997;94:1369-84.

Institute of Scrap Recycling Industries (ISRI). Scrap Specifications Circular 2013. Washington, US2013. International Organization for Standardization (ISO). ISO 683-1: Heat-treatable steels, alloy steel and free-cutting steels-Part 1: Direct-hardening unalloyed and low-alloyed wrought steel in form of different black products. Geneva: ISO1987.

International Organization for Standardization (ISO). ISO 683-14: Heat-treatable steels, alloy steels and free cutting steels-Part 14 : Hot-rolled steels for quenched and tempered springs. Geneva: ISO2004. International Organization of Motor Vehicle Manufactures (OICA). World Motor Vehicle Production.2012 (accessed April 16, 2013). Japan Auto Parts Industries Association. Survey for shipments of automobile parts. 2007. Japan Automobile Dealers Association. Ranking for unit sales of purchased new passenger car 2005,http://www.jada.or.jp/contents/data/ranking/pdf/ranking2005.pdf (accessed January 17, 2014). 
504

505

506

507

Japan Environmental Sanitation Center. Report for implementation of efficient and rational treatment for end of life vehicles. Japan: Japan Environmental Sanitation Center; 2009. Japan Oil, Gas and Metals National Corporation (JOGMEC);. Kobutsu Shigen Material Flow 2006 [Material flow of Metal Resource]. In: JOGMEC, editor. Japan: JOGMEC; 2007. Kondo Y, Nakamura S. Waste input-output linear programming model with its application to eco-efficiency analysis. Econ Syst Res. 2005;17:393-408.

Matsubae K, Iizuka Y, Ohno H, Hiraki T, Miki T, Nakajima K, et al. Distribution Analysis on Steel Alloying Elements in the End of Life Vehicle Scrap Recycling Process. Tetsu-to-Hagane. 2014a;100:788-93.

Matsubae K, Iizuka Y, Osamura H, Ohno H, Nakajima K, Nagasaka T. Cost Benefit Analysis of End of Life Vehicle Origin Scrap Sorting. Tetsu-to-Hagane. 2014b;100:794-8.

Matsubae K, Nakajima K, Nakamura S, Nagasaka T. Impact of the Recovery of Secondary Ferrous Materials from Alternative ELV Treatment Methods on CO2 Emission: A Waste Input Output Analysis. Isij Int. 2011;51:151-7.

Michaelis P, Jackson T. Material and energy flow through the UK iron and steel sector. Part 1: 1954-1994. Resour Conserv Recy. 2000;29:131-56.

Millet D, Yvars P-A, Tonnelier P. A method for identifying the worst recycling case: Application on a range of vehicles in the automotive sector. Resources, Conservation and Recycling. 2012;68:1-13.

Ministry of Economy, Trade and Industry (Japan),; Yearbook of Iron and Steel, Non-ferrous Metals, and Fabricated Metals Statistics. Japan: Ministry of Economy, Trade and Industry; 2006. Ministry of Environment (Japan). The advanced utilization of the end of life vehicle originated scraps: as the technical report of Ministry of Environment, Japan funded project " Advanced metal recycling technology development". Sendai,: Tohoku University; 2012.

Ministry of Industrial Affairs and Communications (Japan). 2005 input-output table for Japan. 2009.

Mueller DB, Wang T, Duval B, Graedel TE. Exploring the engine of anthropogenic iron cycles. Proceedings of the National Academy of Sciences of the United States of America. 2006;103:16111-6.

Nakajima K, Ohno H, Kondo Y, Matsubae K, Takeda O, Miki T, et al. Simultaneous material flow analysis of nickel, chromium, and molybdenum used in alloy steel by means of input-output analysis. Environ Sci Technol. 2013;47:4653-60.

Nakajima K, Takeda O, Miki T, Matsubae K, Nagasaka T. Thermodynamic Analysis for the Controllability of Elements in the Recycling Process of Metals. Environ Sci Technol. 2011;45:4929-36.

Nakajima K, Yokoyama K, Nagasaka T. Substance flow analysis of manganese associated with iron and steel flow in japan. Isij Int. 2008;48:549-53.

Nakamura S, Kondo Y, Kagawa S, Matsubae K, Nakajima K, Nagasaka T. MaTrace: Tracing the Fate of Materials over Time and Across Products in Open-Loop Recycling. Environ Sci Technol. 2014;48:7207-14.

Nakamura S, Kondo Y, Matsubae K, Nakajima K, Nagasaka T. UPIOM: A New Tool of MFA and Its Application to the Flow of Iron and Steel Associated with Car Production. Environ Sci Technol. 2011;45:1114-20.

Nakamura S, Kondo Y, Matsubae K, Nakajima K, Tasaki T, Nagasaka T. Quality- and dilution losses in the recycling of ferrous materials from end-of-life passenger cars: input-output analysis under explicit consideration of scrap quality. Environ Sci Technol. 2012;46:9266-73. 
Nakamura S, Nakajima K. Waste input-output material flow analysis of metals in the Japanese economy. Mater Trans. 2005;46:2550-3.

Nakamura S, Nakajima K, Kondo Y, Nagasaka T. The waste input-output approach to materials flow analysis - Concepts and application to base metals. Journal of Industrial Ecology. 2007;11:50-63.

Nuss P, Harper EM, Nassar NT, Reck BK, Graedel TE. Criticality of Iron and Its Principal Alloying Elements. Environ Sci Technol. 2014;48:4171-7. Oda T, Daigo I, Matsuno Y, Adachi Y. Substance Flow and Stock of Chromium Associated with Cyclic Use of Steel in Japan. Tetsu to Hagane. 2009;95:A720-A9.

Ohno H, Matsubae K, Nakajima K, Nakamura S, Nagasaka T. Unintentional Flow of Alloying Elements in Steel during Recycling of End-of-Life Vehicles. Journal of Industrial Ecology. 2014;18:242-53.

Pauliuk S, Wang T, Mueller DB. Moving Toward the Circular Economy: The Role of Stocks in the Chinese Steel Cycle. Environ Sci Technol. 2012;46:148-54.

Reck BK, Chambon M, Hashimoto S, Graedel TE. Global Stainless Steel Cycle Exemplifies China's Rise to Metal Dominance. Environ Sci Technol. 2010;44:3940-6.

Reck BK, Graedel TE. Challenges in Metal Recycling. Science. 2012;337:690-5. Simic V, Dimitrijevic B. Risk explicit interval linear programming model for long-term planning of vehicle recycling in the EU legislative context under uncertainty. Resources, Conservation and Recycling. 2013;73:197-210.

Special Steel Association of JAPAN. Report for the trend of special steel usages according to technical innovation of automobiles. 2002.

Tasaki T, Hashimoto S, Terazono A, Moriguchi Y. Product-level material flow anylsis: A case study of car in Japan. ConAccount Meeting 2004 Book of Abstracts. 2004.

The Japan Ferrous Raw Materials Association. Tetsugen Nenpo 2006 [ Annual report of ferrous raw materials for 2005]. Japan: The Japan Ferrous Raw Materials Association,; 2006. The Japan Ferrous Raw Materials Association. Uniform Standards of Ferrous Scraps. Tokyo, Japan2008.

The Japan Iron and Steel Federation. Order Booked of Steel Products. Tokyo: The Japan Iron and Steel Federation,,2013,http://www.jisf.or.jp/en/statistics/order/TimeSeries.html (accessed November 22, 2013). Wang T, Mueller DB, Graedel TE. Forging the anthropogenic iron cycle. Environ Sci Technol. 2007;41:5120-9. 